\title{
Effects of Manuka Honey Combined with $\alpha$-Cyclodextrin on Bone Metabolism and Caecal Bacterial Contents in Ovariectomized Mice
}

\author{
Shinichi Katsumata ${ }^{1,2}$, Frances M. Wolber ${ }^{1}$, Miki Tadaishi' ${ }^{2,3}$, Yuko Tousen ${ }^{3}$, Yoshiko Ishimi ${ }^{3}$, \\ Marlena C. Kruger ${ }^{*}$
}

${ }^{1}$ Institute of Food, Nutrition and Human Health, Massey University, Palmerston North, New Zealand

${ }^{2}$ Department of Nutritional Science, Faculty of Applied Bioscience, Tokyo University of Agriculture, Tokyo, Japan

${ }^{3}$ Department of Food Function and Labeling, National Institute of Health and Nutrition, Tokyo, Japan

Corresponding author: Kruger, M.C. Institute of Food, Nutrition and Human Health, Massey University, Palmerston, New Zealand. Tel: +64-6-350-5905; Fax:+64-6-350-5446; E-mail: M.C.Kruger@massey.ac.nz

\begin{abstract}
Honey has antimicrobial, antitumor, antioxidant, and anti-inflammatory effects. However, there have been few studies regarding the effects of manuka honey on bone metabolism and gut microflora. This study investigated the effects of manuka honey combined with $\alpha$-cyclodextrin, Manuka Honey with Cyclopower ${ }^{\mathrm{TM}}$ (MHCP) on bone metabolism and caecal bacterial contents in ovariectomized (OVX) mice. Seven-week-old female Balb/c-strain mice were divided into four groups: sham-operated (sham) group, OVX group, and OVX mice that were fed a diet containing 5\% or $10 \%(\mathrm{w} / \mathrm{w})$ MHCP. After 9 weeks, the mice were sacrificed, and serum, uterus, caecum, and femur samples were obtained. Successful removal of the ovaries and induction of the osteoporotic process in OVX mice were demonstrated by a significant decrease in uterine weight and a significant increase in receptor activator of NF- $\kappa \mathrm{B}$ ligand (RANKL) mRNA expression of the femur, compared to sham, respectively. Compared to the OVX group, MHCP reduced serum $\mathrm{C}$-terminal telopeptide of type I collagen concentration as well as RANKL and nuclear factor of activated T-cells c1 (NFATc1) mRNA expression of the femur. Furthermore, MHCP increased caecal bifidobacteria and bacteroides contents. These results suggest that the MHCP expressed prebiotic effects, which might reduce bone resorption in OVX mice.
\end{abstract}

Keywords: Manuka Honey with Cyclopower ${ }^{\mathrm{TM}}$; Bone resorption; Receptor activator of NF- $\kappa \mathrm{B}$ ligand; Caecal bacterial contents; Ovariectomized mice

\section{Introduction}

Honey is a natural food product and mainly consists of several sugars. Moreover, it also contains food factors such as proteins, vitamins, minerals, and polyphenols ${ }^{[1]}$. Previous studies have shown that honey has antimicrobial, antitumor, antioxidant, and anti-inflammatory effects ${ }^{[2]}$. In addition, a previous study demonstrated that honey intake caused significant reduction of body mass index (BMI) and fasting blood glucose in overweight and obese subjects, and significantly reduced serum triglyceride and C-reactive protein (CRP) in the subjects with elevated variables $^{[3]}$. Therefore, honey is expected to have several benefits for human health possibly including an effect on bone health.

A previous study has shown that administration of honey for 2 weeks to ovariectomized (OVX) rats restored the morphology of the tibia bones ${ }^{[4]}$. In addition, honey improved the trabecular structure of bone as assessed using histomorphometry in OVX rats that were orally gavaged daily for 6 weeks ${ }^{[5]}$. Thus, honey may prevent bone loss due to menopause. Furthermore, honey enhanced the endogenous colonic
Received Date: April 16, 2015

Accepted Date: July 30, 2015

Published Date: Aug 03, 2015

Citation: Kruger, M.C. et al. Effects of Manuka Honey Combined with $\alpha$-Cyclodextrin on Bone Metabolism and Caecal Bacterial Contents in Ovariectomized Mice. (2015) J Food Nutr Sci 2(2): 86-91.

DOI: $10.15436 / 2377-0619.15 .021$

probiotic bacteria in mice ${ }^{[6]}$, which indicates that honey may act as a prebiotic in the large intestine.

Cyclodextrin has been used as excipient for the delivery of hydrophobic drugs and improving water solubility and stability $^{[7]}$. Recently, manuka honey combined with $\alpha$-cyclodextrin (Manuka Honey with Cyclopower ${ }^{\mathrm{TM}}$ (MHCP)) has been produced and tested. The results showed that MHCP retained antibacterial activity, and enhanced bacteriostatic and possibly bactericidal activity against Gram-negative and Gram-positive pathogens ${ }^{[8]}$. Manuka honey is a wellknown product of New Zealand, and contains high amounts of methylglyoxal (MGO). MGO acts as a bioactive compound which is responsible for the antibacterial activity ${ }^{[9]}$. It was reported that manuka honey had a potent inhibitory activity against the influenza virus $^{[10]}$. However, there had been few studies regarding the effects of manuka honey on bone metabolism and gut microflora, whereas some studies were conducted by

Copy rights: (C2015 Kruger, M.C. This is an Open access article distributed under the terms of Creative Commons Attribution 4.0 International License. 
using other species of honey as stated above ${ }^{[4-6]}$. Therefore, this study investigated the effects of MHCP on bone metabolism and caecal bacterial contents in OVX mice.

\section{Methods}

This study was approved by the Massey University Animal Ethics Committee (approval number 13/38).

\section{Experimental Design}

Five-week old female Balb/c mice were purchased from the Vernon Jenson Unit (VJU, University of Auckland, Auckland, New Zealand) and housed 2-3 mice per plastic cage at $22^{\circ} \mathrm{C}$ with a 12 -h light/dark cycle in a dedicated room. Throughout the study period, the mice were fed their allocated control diet, $5 \%$ honey diet, or $10 \%$ honey diet, as shown in Table 1. Manuka Honey with CycloPower ${ }^{\mathrm{TM}}$ (MHCP, Manuka Health New Zealand Ltd, Auckland, New Zealand) was used in this study. It is manufactured by combining MGO400+ manuka honey and $\alpha$-cyclodextrin, which is $45 \%$ honey solids plus $55 \%$ $\alpha$-cyclodextrin ${ }^{[8]}$. MGO400+ manuka honey has MGO level of $400 \mathrm{mg} / \mathrm{kg}$ or greater. All mice were fed the control diet for 2 weeks of acclimatization period. After 2 weeks, 7-week-old mice were sham-operated (sham) or OVX. Sham mice were fed the control diet. OVX mice were divided into three groups: one OVX group was fed the control diet and the two remaining OVX groups received the $5 \%$ or $10 \%$ honey diet. All mice were given free access to their respective diets and deionized water for 9 weeks. At the end of the study period, all mice were sacrificed, and the blood, uterus, caecum, and femur samples were obtained for further analyses. The uterus, caecum, and caecal contents were weighed.

Table 1: Composition of the experimental diets

\begin{tabular}{|c|c|c|c|}
\hline & Control & $5 \%$ honey & $10 \%$ honey \\
\hline \multicolumn{4}{|c|}{$\mathrm{g} / 1 \mathrm{~kg}$ diet } \\
\hline Sodium caseinate & 150.0 & 150.0 & 150.0 \\
\hline Cystine & 2.7 & 2.7 & 2.7 \\
\hline Glycine & 3.3 & 3.3 & 3.3 \\
\hline Methionine & 1.5 & 1.5 & 1.5 \\
\hline Glutamine & 7.0 & 7.0 & 7.0 \\
\hline Cornstarch & 463.0 & 463.0 & 463.0 \\
\hline Sucrose & 200.0 & 150.0 & 100.0 \\
\hline Corn oil & 50.0 & 50.0 & 50.0 \\
\hline Cellulose powder & 50.0 & 50.0 & 50.0 \\
\hline Mineral mixture ${ }^{\mathrm{a}}$ & 50.0 & 50.0 & 50.0 \\
\hline Calcium carbonate & 12.5 & 12.5 & 12.5 \\
\hline Vitamin mixture ${ }^{b}$ & 10.0 & 10.0 & 10.0 \\
\hline $\begin{array}{l}\text { Manuka Honey with Cyclo- } \\
\text { power }^{\mathrm{TM}}\end{array}$ & - & 50.0 & 100.0 \\
\hline
\end{tabular}

${ }^{\mathrm{a}} \mathrm{AIN}-93 \mathrm{M}$ mineral mixture [11] without calcium carbonate ${ }^{\mathrm{b}} \mathrm{AIN}-93$ vitamin mixture [11]

\section{Dual-Energy X-ray Absorptiometry (DXA) Scans}

At weeks 4 and 8, all mice underwent in vivo DXA scanning under anesthesia. Bone mineral content (BMC), bone mineral density (BMD), and body fat were measured with a Ho- logic Discovery A bone densitometer (Hologic Inc., MA, USA). Each mouse underwent a high-resolution scan of the whole body.

\section{Measurement of Markers of Bone Turnover}

The blood samples were centrifuged at $3000 \times \mathrm{g}$ for 15 minutes and the serum supernatants were stored at $-80^{\circ} \mathrm{C}$ until further analyses. Serum osteocalcin concentration was measured using the Mouse Gla-Osteocalcin High Sensitive EIA Kit (Takara Bio Inc., Shiga, Japan). Serum C-terminal telopeptide of type I collagen (CTx) concentration was measured using RatLaps EIA (Immunodiagnostics systems, Boldon, UK).

\section{Total RNA Extraction and Real-Time Reverse Transcrip- tion-Polymerase Chain Reaction (RT-PCR) Analysis of mRNA Expression}

The right femur was removed and cleansed of all soft tissues and was frozen at $-80^{\circ} \mathrm{C}$ until further analysis. Frozen right femur was homogenized in $1.6 \mathrm{ml}$ TRIzol reagent (Life Technologies, CA, USA) using the Precellys homogenizer in tubes containing ceramic $2.8 \mathrm{~mm}$ beads and one $5 \mathrm{~mm}$ zinc oxide bead (Precellys) at $6500 \mathrm{rpm}$ for 20 seconds. Total RNA was isolated from the lysate by using Direct-zol RNA MiniPrep kit (Zymo Research, CA, USA) according to the manufacturer's instructions. The cDNA was synthesized using the SuperScript III First-Strand Synthesis SuperMix for qRT-PCR (Life Technologies) and was subjected to quantitative real-time RT-PCR using SYBR Select Master Mix (Life Technologies). Specific primers ${ }^{[12,13]}$ were used for the analysis of receptor activator of NF- $\kappa$ B ligand (RANKL) (forward, 5'-TGAAGACACACTACCTGACTCCTG-3'; reverse, '-CCACAATGTGTTGCAGTTCC-3'), nuclear factor of activated T-cells c1 (NFATc1) (forward, 5'-CCGTGCTTCCAGAAAATAACA-3'; reverse, 5'-TGTGGGATGTGAACTCGGAA-3'), and $\beta$-actin (forward, 5'-TGACAGGATGCAGAAGGAGA-3'; reverse, 5'-CGCTCAGGAGGAGCAATG-3'). Real-time RT-PCR was performed on a Light Cycler 480 System (Roche, Mannheim, Germany). The mRNA expression was normalized to $\beta$-actin mRNA as a housekeeping gene.

\section{DNA Extraction and Bacteria Quantification by Real-Time PCR}

Caecal contents were removed and frozen at $-80^{\circ} \mathrm{C}$ until further analysis. The DNA was extracted from the caecal contents by using ISOLATE Fecal DNA kit (Bioline, London, UK) according to the manufacturer's instructions. To quantify lactobacillus, bifidobacteria, and bacteroides, the specific primers $^{[14-16]}$ were used for the analysis of lactobacillus (forward, 5'-GGAAACAGRTGCTAATACCG-3'; reverse, 5'-ATCGTATTACCGCGGCTGCTGGCA-3'), bifidobacteria (forward, 5'-TCGCGTCYGGTGTGAAAG-3'; reverse, 5'-CCACATCCAGCRTCCAC-3'), and bacteroides (forward, 5'-GAGAGGAAGGTCCCCCAC-3'; reverse, 5'-CGCTACTTGGCTGGTTCAG-3'). Real-time PCR was performed on a Light Cycler 480 System (Roche). The PCR reaction was performed using the Light Cycler 480 SYBR Green I Master (Roche). 


\section{Statistical Analysis}

Results were expressed as mean \pm standard error of the mean (SEM). Data were analyzed by one-way analysis of variance (ANOVA), followed by Turkey's post hoc testing. Differences were considered to be significant when the $p$ value was less than 0.05. Statistical analysis was performed using SPSS statistics ver. 21 (IBM, IL, USA).

\section{Results}

\section{Body Weight and Uterine Weight}

Initial and final body weights did not differ significantly among the four groups (Table 2). Body weight gain was significantly higher in the OVX group than in the sham group, whereas there was no significant difference in body weight gain between the OVX and $5 \%$ or $10 \%$ honey groups. Uterine weight was significantly lower in the OVX group than in the sham group. The $5 \%$ and $10 \%$ honey diet did not affect uterine weight in the OVX mice.

Table 2: Body weight, organ weight, and fat of the whole body

\begin{tabular}{|c|c|c|c|c|}
\hline \multicolumn{1}{|c|}{$\begin{array}{c}\text { Shitial body } \\
\text { weight(g) }\end{array}$} & $19.7 \pm 0.4$ & $19.6 \pm 0.6$ & $19.3 \pm 0.4$ & $19.1 \pm 0.4$ \\
\hline $\begin{array}{c}\text { Final body weight } \\
\text { (g) }\end{array}$ & $27.8 \pm 0.7$ & $32.2 \pm 1.8$ & $30.2 \pm 1.1$ & $29.4 \pm 1.1$ \\
\hline $\begin{array}{c}\text { Body weight gain } \\
\text { (g) }\end{array}$ & $8.1 \pm 0.7^{\mathrm{a}}$ & $12.6 \pm 1.3^{\mathrm{b}}$ & $10.9 \pm 0.9^{\mathrm{ab}}$ & $10.3 \pm 0.7^{\mathrm{ab}}$ \\
\hline Uterus (mg) & $141.3 \pm 12.2^{\mathrm{a}}$ & $42.6 \pm 5.2^{\mathrm{b}}$ & $36.9 \pm 3.3^{\mathrm{b}}$ & $38.9 \pm 6.2^{\mathrm{b}}$ \\
\hline Caecum (mg) & $86.4 \pm 10.4$ & $91.2 \pm 22.0$ & $85.9 \pm 8.8$ & $104.0 \pm 5.7$ \\
\hline $\begin{array}{c}\text { Caecal contents } \\
(\mathrm{mg})\end{array}$ & $93.6 \pm 6.4^{\mathrm{a}}$ & $125.8 \pm 11.3^{\mathrm{a}}$ & $179.9 \pm 14.9^{\mathrm{b}}$ & $187.7 \pm 13.7^{\mathrm{b}}$ \\
\hline Week 4 & $6.0 \pm 0.6^{\mathrm{ab}}$ & $8.1 \pm 1.0^{\mathrm{a}}$ & $6.1 \pm 0.6^{\mathrm{ab}}$ & $5.4 \pm 0.4^{\mathrm{b}}$ \\
\hline Fat (g) & $26.6 \pm 2.0$ & $30.4 \pm 2.5$ & $25.0 \pm 2.1$ & $22.6 \pm 1.4$ \\
\hline Fat (\%) & $10.3 \pm 0.9$ & $13.1 \pm 1.6$ & $10.6 \pm 1.3$ & $9.0 \pm 1.0$ \\
\hline Week 8 & $37.7 \pm 2.6$ & $40.0 \pm 3.1$ & $34.9 \pm 3.1$ & $30.8 \pm 2.3$ \\
\hline Fat (g) & \multicolumn{5}{|c}{} \\
\hline Fat (\%) & \multicolumn{5}{|c|}{} \\
\hline
\end{tabular}

Data are presented as the means \pm SEM of 9 or 10 mice.

${ }^{a, b}$ Different superscript letters denote significantly different among the groups, $\mathrm{p}<0.05$.

\section{BMC, BMD, and Fat of Whole Body}

At weeks 4 and 8, BMC and BMD of the whole body did not differ significantly between the sham and OVX groups and between the OVX and $5 \%$ or $10 \%$ honey groups (data not shown). At week 4 , there was no significant difference in body fat percentage among the four groups (Table 2). Whole body fat content did not differ significantly between the sham and OVX groups and was significantly lower in the $10 \%$ honey group than in the OVX group at week 4. At week 8, there were no significant differences in whole body fat content and body fat percentage among the four groups.

\section{Markers of Bone Turnover}

Serum osteocalcin concentration did not differ significantly among the four groups (Figure 1). Serum CTx concentration did not differ significantly between the sham and OVX groups. Compared to the OVX group, the 5\% honey diet tended to decrease $(p=0.06)$ and the $10 \%$ honey diet significantly de- creased $(\mathrm{p}<0.05)$ serum CTx concentration.

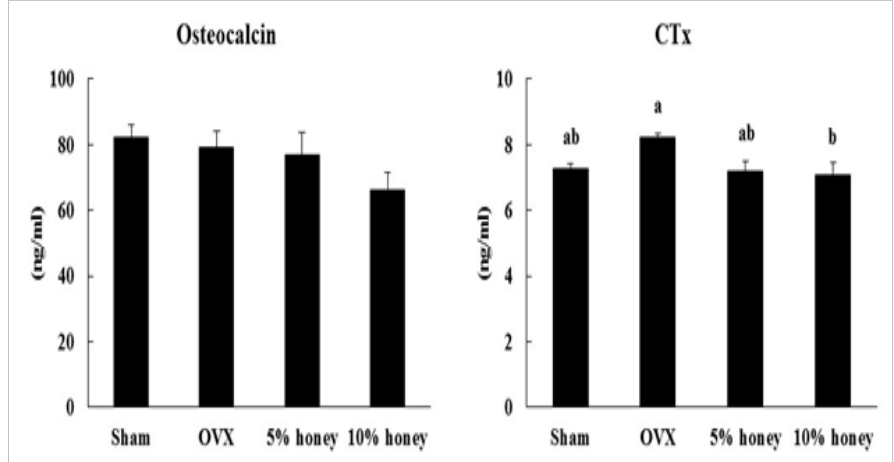

Figure 1: Effect of Manuka Honey with Cyclopower ${ }^{\mathrm{TM}}$ on markers of bone turnover. Sham, sham-operated mice fed a control diet; OVX, ovariectomized mice fed a control diet; $5 \%$ honey, ovariectomized mice fed a $5 \%$ honey diet; $10 \%$ honey, ovariectomized mice fed a $10 \%$ honey diet. Data are presented as mean \pm SEM. ${ }^{\mathrm{a}, \mathrm{b}}$ Different letters denote significantly different, $\mathrm{p}<0.05$.

\section{RANKL and NFATc1 mRNA Expression of the Femur}

RANKL mRNA expression of the femur was significantly higher in the OVX group than in the sham group (Figure 2). Compared to the OVX group, the $5 \%$ and $10 \%$ honey diets significantly decreased RANKL mRNA expression of the femur. NFATc1 mRNA expression of the femur was significantly lower in the 5\% and $10 \%$ honey groups than in the OVX group, whereas there was no significant difference in NFATc1 mRNA expression of the femur between the sham and OVX groups.
RANKL

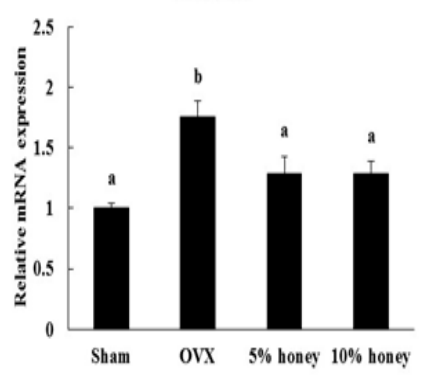

NFATc1

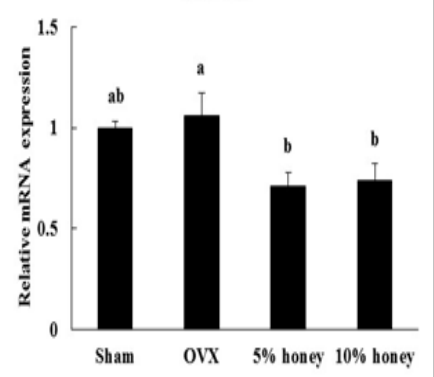

Figure 2: Effect of Manuka Honey with Cyclopower ${ }^{\mathrm{TM}}$ on RANKL and NFATc1 mRNA expression of the femur. Sham, sham-operated mice fed a control diet; OVX, ovariectomized mice fed a control diet; $5 \%$ honey, ovariectomized mice fed a $5 \%$ honey diet; $10 \%$ honey, ovariectomized mice fed a $10 \%$ honey diet. Data are expressed as mean \pm SEM. ${ }^{a, b}$ Different letters denote significantly different, $\mathrm{p}<0.05$.

\section{Caecum Weight and Caecal Bacterial Contents}

There were no significant differences in the caecal organ weight among the four groups (Table 1). The weight of caecal contents did not differ significantly between the sham and OVX groups but was significantly higher in the 5\% and $10 \%$ honey groups compared to the OVX group.

There was no significant difference in lactobacillus content among the four groups (Figure 3). Bifidobacteria content did not differ significantly between the sham and OVX groups but was significantly higher in the $10 \%$ honey group than in the OVX group. Bacteroides content did not differ significantly between the sham and OVX groups but was significantly higher in the $5 \%$ and $10 \%$ honey groups than in the OVX group. 


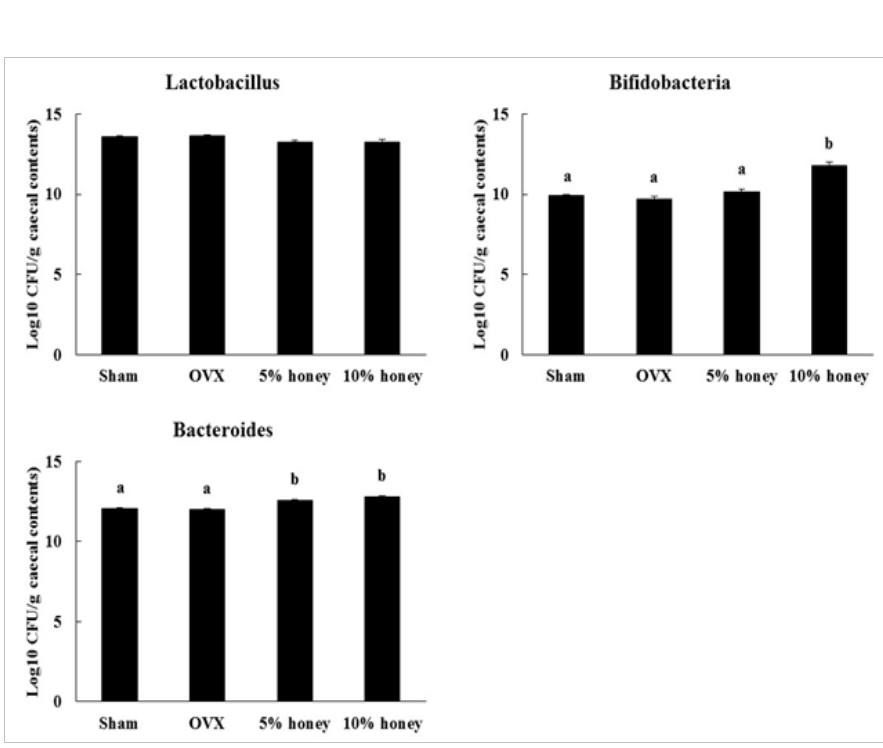

Figure 3: Effect of Manuka Honey with Cyclopower ${ }^{\mathrm{TM}}$ on caecal bacterial contents. Sham, sham-operated mice fed a control diet; OVX, ovariectomized mice fed a control diet; 5\% honey, ovariectomized mice fed a $5 \%$ honey diet; $10 \%$ honey, ovariectomized mice fed a $10 \%$ honey diet. Data are expressed as mean \pm SEM. ${ }^{a, b}$ Different letters denote significantly different, $\mathrm{p}<0.05$.

\section{Discussion}

In this study, serum CTx concentration was increased by about $13 \%$ in the OVX group compared to the sham group, although this was not statistically significant. However, RANKL mRNA expression of the femur was significantly higher in the OVX group than in the sham group. RANKL is an osteoclast differentiation factor and plays a key role in osteoclastic bone resorption $^{[17]}$. Therefore, the results suggest that ovariectomy caused an increase in osteoclast differentiation in this study. Uterine weight decreases following total ovariectomy, and body weight gain increases in OVX animals. Weight gain, as well as development of osteoporosis, is a concern for women following menopause. In this study, the uterine weights of OVX group were reduced and the rate of gain of body weight increased compared to the sham group. Taken together, these findings show that this model successfully induced early osteoporotic pathogenesis.

Previous studies showed that tualang honey improved the trabecular structure of bone in OVX rats ${ }^{[4,5]}$. We used MHCP in this study, and the $5 \%$ honey diet tended to decrease $(p=0.06)$ and the $10 \%$ honey diet significantly decreased serum CTx concentration in OVX mice without a change in uterine weight. Furthermore, RANKL and NFATc1 mRNA expression of the femur were significantly lower in the $5 \%$ and $10 \%$ honey groups than in the OVX group. It is known that NFATc1 mediates osteoclast differentiation as a key regulator responsive to RANKL ${ }^{[18]}$. RANKL induces TNF receptor-associated factor 6 (TRAF6) and c-Fos expression during osteoclastogenesis and the pathways related these molecules play important roles in NFATc1 expression. Therefore, MHCP may inhibit RANKL mRNA expression, which leads to a decrease in NFATc1 mRNA expression. Further studies may be needed to investigate the changes in molecules that are related with RANKL-NFATc1 signal pathway, such as TRAF6 and c-Fos. Osteoprotegerin (OPG) is known as a decoy receptor for RANKL and is also an important factor for osteoclastogenesis $^{[19]}$. We did not measure OPG mRNA expression of the femur in this study, but a recent study showed that ovariectomy increased serum RANKL concentration but did not change serum OPG concentration in rats ${ }^{[20]}$. However, the effect of MHCP on OPG mRNA expression remains unknown, and further studies are necessary for clarification. These results suggest that MHCP inhibited RANKL-induced osteoclast differentiation, which led to a decrease in bone resorption in OVX mice. In this study, there were no significant differences in BMC and BMD of the whole body between the sham and OVX groups and between the OVX and $5 \%$ or $10 \%$ honey groups as measured by DXA scanning, whereas uterine weight was significantly lower in the OVX group than in the sham group. The measurement using the DXA machine was possibly not sensitive enough to detect any differences in BMC and BMD. For mice, other instruments are usually used. Also in general, trabecular bone is more affected than cortical bone by ovariectomy. A previous study showed that ovariectomy caused a decrease in trabecular bone volume of the distal femur and an increase in RANKL mRNA expression of bone marrow cells from the tibia, whereas there was no significant difference in whole femur $\mathrm{BMD}^{[21]}$. It may be of benefit to rather measure the trabecular bone volume by bone histomorphometry or $\mu \mathrm{CT}$ in the further studies with mice. Furthermore, body weight gain was significantly higher in the OVX group than in the sham group in this study. Therefore, an increase in body weight gain might have influenced BMD in the OVX group.

Honey is rich in polyphenols, and quercetin and kaempherol are found in honey ${ }^{[1]}$. However, the type and concentration of these compounds are known to vary depending on geographical location and floral source. Manuka honey produced in New Zealand contains large amount of quercetin and kaempherol compared with other species of honey ${ }^{[2]}$. Previous studies reported that quercetin inhibited a decrease in BMD in OVX mice, and quercetin suppressed the RANKL-induced NFATc1 expression and osteoclast formation in RAW264.7 cells $^{[23]}$. Likewise, kaempherol inhibited interleukin-1 $\beta$-stimulated, RANKL-mediated osteoclastogenesis via downregulation of NFATc1 in mouse bone marrow cells ${ }^{[24]}$. In addition, manuka honey is also rich in luteolin ${ }^{[22]}$, which has a preventive effect of OVX-induced bone loss and inhibition of osteoclast formation in RAW264.7 cells ${ }^{[25]}$. Thus, polyphenols such as quercetin, kaempherol, and luteolin in the manuka honey could also have contributed to suppression of bone resorption in OVX mice. High concentration of MGO is characteristic in the manuka honey, and MGO contributes to the antibacterial activity ${ }^{[9]}$. However, there are no studies about the effects of MGO on bone metabolism, and detailed examinations are necessary for clarification.

Prebiotics such as fructooligosaccharides have been found to increase the numbers of bifidobacterium and lactobacillus in rats ${ }^{[26]}$. Fermentation in the large intestine produces short chain fatty acids (SCFAs) and other organic acids that contribute to lower luminal $\mathrm{pH}$ in the large intestine which, in turn, elicits a modification of calcium solubility in the luminal phase so that its passive diffusion is improved ${ }^{[27]}$. In addition, SCFAs are also likely to contribute directly to the enhancement of calcium absorption ${ }^{[28]}$. Thus, prebiotics such as oligosaccharides have been found to stimulate calcium absorption, which have a beneficial effect on bone health. A previous study has shown 
that cotton honey enhanced the endogenous colonic probiotic bacteria in mice ${ }^{[6]}$. In this study, the weight of caecal contents was significantly higher in the $5 \%$ and $10 \%$ honey groups than in the OVX group, whereas caecal organ weight did not differ. Furthermore, caecal bifidobacteria content was significantly higher in the $10 \%$ honey group than in the OVX group, and caecal bacteroides content was significantly higher in the $5 \%$ and $10 \%$ honey groups than in the OVX group. These results suggest that MHCP enhanced caecal probiotic bacteria. It is well known that honey contains oligosaccharides such as fructooligosaccharide, and manuka honey also contains oligosaccharides ${ }^{[29]}$. Therefore, we speculate that oligosaccharides in the MHCP expressed a prebiotic effect, which may have a beneficial effect on bone resorption in OVX mice. Furthermore, acute feeding of honey and its carbohydrate constituents (glucose, fructose, and raffinose) enhanced calcium absorption in rats ${ }^{[30]}$. Thus, carbohydrate constituents of the MHCP might have also increased calcium absorption in this study.

Cyclodextrin have been used as excipients for the delivery of hydrophobic drugs and improving water solubility and stability ${ }^{[7]}$. Since cyclodextrin is a non-digestible sugar, fermentation in the large intestine may have occurred in this study. In fact, $5 \% \alpha$-cyclodextrin in the diet increased weights of caecal tissue and caecal contents and amount of caecal organic acids contents in $\operatorname{rats}^{[31]} \cdot \alpha$-Cyclodextrin may therefore stimulate caecal fermentation, leading to an increase in caecal organic acids contents. MHCP used in this study contains 55\% $\alpha$-cyclodex$\operatorname{trin}^{[8]}$, and the percentage of $\alpha$-cyclodextrin in the $10 \%$ honey diet was $5.5 \%$ in this study. Therefore, oligosaccharides as well as $\alpha$-cyclodextrin may have influenced cecal bacterial contents. In this study, $10 \%$ honey diet significantly decreased whole body fat content at week 4 in OVX mice, although there is no significant difference in body weight at week 4 between the OVX $(26.9 \pm 1.6 \mathrm{~g})$ and $10 \%$ honey $(24.9 \pm 0.9 \mathrm{~g})$ groups. A previous study demonstrated that mean total percent body fat was lower in honey-fed rats than in sucrose-fed rats without change in food intake $^{[32]}$. The mechanism by which honey reduced body fat is still not clear, but polyphenols and oligosaccharide in the honey might influence whole body fat content. Quercetin reduced fat accumulation in mice with high fat diet-induced obesity ${ }^{[33]}$. Furthermore, fructo-oligosaccharide increased the bioavailability of quercetin, which augmented benefits of quercetin in sucrose-fed rats $^{[34]}$. Thus, polyphenols and oligosaccharides in the MHCP may have decreased whole body fat content of the OVX mice in this study.

The present study has some limitations: The actual chemical composition of the MHCP used in this study was not analysed and the specific effects of manuka honey without $\alpha$-cyclodextrin was not tested. A previous study showed that the MHCP maintained anti-oxidant capacity and increased anti-inflammatory effect compared to manuka honey that has a MGO level of $400 \mathrm{mg} / \mathrm{kg}$ or greater ${ }^{[35]}$. Also, another study demonstrated that manuka honey was an effective antibacterial agent that can be enhanced by complexing with $\alpha$-cyclodextrin ${ }^{[8]}$. Thus, it is possible that inclusion of manuka honey in $\alpha$-cyclodextrin maintains or promotes the effects of manuka honey. We can therefore not explain which component in the honey could have had the significant effect and further research is required to investigate the selective effects of manuka honey in the presence and absence of $\alpha$-cyclodextrin.

\section{Conclusion}

We demonstrated the effects of MHCP on bone metabolism and caecal bacterial contents in OVX mice. MHCP decreased serum CTx concentration and femoral RANKL and NFATc1 mRNA expression without any effect on uterine weight in OVX mice. In addition, MHCP increased caecal bifidobacteria and bacteroides contents. These results suggested that the MHCP expressed prebiotic effects, which may have caused a decrease in bone resorption in OVX mice.

\section{Conflicts of Interest}

The authors declare no conflicts of interest.

\section{Acknowledgement}

This study was funded by New Zealand (Minister of Business, Innovation and Employment) and Japan (Japanese Science and Technology Agency) of the Strategic Bilateral Agreement Program on Functional Foods. The authors would like to thank A. Broomfield, K. Wylie, G. Plimmer, Z. Liu, C. Hulls, and S. De (IFNHH, Massey University, Palmerston North, New Zealand) for excellent technical assistance and Manuka Health New Zealand Ltd for supplying the Manuka Honey with Cyclopower $^{\mathrm{TM}}$ product.

\section{References}

1. Jaganathan, S.K., Mandal, M. Antiproliferative effects of honey and of its polyphenols: a review. (2009) J Biomed Biotechnol.

2. Bogdanov, S., Jurendic, T., Sieber, R., et al. Honey for nutrition and health: a review. (2008) J Am CollNutr 27 (6): 677-689.

3. Yaghoobi, N., Al-Waili, N., Ghayour-Mobarhan, M., et al. Natural honey and cardiovascular risk factors; effects on blood glucose, cholesterol, triacylglycerole, CRP, and body weight compared with sucrose. (2008) ScientificWorldJournal 8: 463-469.

4. Zaid, S.S., Sulaiman,S.A., Sirajudeen, K.N., et al. The effects of Tualang honey on female reproductive organs, tibia bone and hormonal profile in ovariectomised rats-animal model for menopause. (2010) BMC Complement Altern Med 10: 82.

5. Zaid, S.S.M., Sulaiman, S.A., Othman, N.H., et al. Protective effects of Tualang honey on bone structure in experimental postmenopausal rats. (2012) Clinics (Sao Paulo) 67(7): 779-784.

6. Ezz El-Arab, A.M., Girgis, S.M., Hegazy, E.M., et al. Effect of dietary honey on intestinal microflora and toxicity of mycotoxins in mice. (2006) BMC Complement Altern Med 6: 6.

7. Stella, V.J., He, Q. Cyclodextrins. (2008) ToxicolPathol 36(1): 30-42. 8. Swift, S., Chepulis, L.M., Uy, B., et al. Enhanced antibacterial activity of MGOTMmanuka honey complexed with $\alpha$-cyclodextrin (Manuka Honey with Cyclopower ${ }^{\mathrm{TM}}$ ). (2014) Funct Food Health Dis 4(5): 172181.

9. Mavric, E., Wittmann, S., Barth, G., et al. Identification and quantification of methylglyoxal as the dominant antibacterial constituent of Manuka (Leptospermum scoparium) honeys from New Zealand. (2008) MolNutr Food Res 52(4): 483-489.

10. Watanabe, K., Rahmasari, R., Matsunaga, A., et al. Anti-influenza viral effects of honey in vitro: potent high activity of manuka honey. (2014) Arch Med Res 45(5): 359-365.

11. Reeves, P.G., Nielsen, F.H., Fahey, G.C.Jr. AIN-93 purified diets for laboratory rodents: final report of the American Institute of Nutrition ad hoc writing committee on the reformulation of the AIN-76A rodent diet. (1993) J Nutr 123(11): 1939-1951.

12. Fujita, K., Janz, S. Attenuation of WNT signaling by DKK-1 and2 regulates BMP2-induced osteoblast differentiation and expression of OPG, RANKL and M-CSF. (2007) Mol Cancer 6: 71. 
13. Liou, S.F., Hsu, J.H., Lin, I.L., et al. KMUP-1 suppresses RANKL-induced osteoclastogenesis and prevents ovariectomy-induced bone loss: roles of MAPKs, Akt, NF- $\mathrm{KB}$ and calcium/calcineurin/NFATc1 pathways. (2013) PLoS One 8(7): e69468.

14. Collier, C.T., Smiricky-Tjardes, M.R., Albin, D.M., et al. Molecular ecological analysis of porcine ilealmicrobiota responses to antimicrobial growth promoters. (2003) J AnimSci 81(12): 3035-3045.

15. Rinttilä, T., Kassinen, A., Malinen, E., et al. Development of an extensive set of $16 \mathrm{~S}$ rDNA-targeted primers for quantification of pathogenic and indigenous bacteria in fecal samples by real-time PCR. (2004) J ApplMicrobiol 97(6): 1166-1177.

16. Layton, A., McKay, L., Williams, D., et al. Development of Bacteroides 16S rRNA gene TaqMan-based real-time PCR assays for estimation of total, human, and bovine fecal pollution in water. (2006) Appl Environ Microbiol 72(6): 4214-4224.

17. Takahashi, N., Udagawa, N., Suda, T. A new member of tumor necrosis factor ligand family, ODF/OPGL/TRANCE/RANKL, regulates osteoclast differentiation and function. (1999) BiochemBiophys Res Commun 256(3): 449-455.

18. Takayanagi, H., Kim, S., Koga, T., et al. Induction and activation of the transcription factor NFATc1 (NFAT2) integrate RANKL signaling in terminal differentiation of osteoclasts. (2002) Dev Cell 3(6): 889-901. 19. Yasuda, H., Shima, N., Nakagawa, N., et al. Identity of osteoclastogenesis inhibitory factor (OCIF) and osteoprotegerin (OPG): a mechanism by which OPG/OCIF inhibits osteoclastogenesis in vitro. (1998) Endocrinology 139(3): 1329-1337.

20. Stolina, M., Dwyer, D., Niu, Q.T., et al. Temporal changes in systemic and local expression of bone turnover markers during six months of sclerostin antibody administration to ovariectomized rats. (2014) Bone 67: 305-313.

21. Nishide, Y., Tadaishi, M., Kobori, M., et al. Possible role of S-equol on bone loss via amelioration of inflammatory indices in ovariectomized mice. (2013) J ClinBiochemNutr 53(1): 41-48.

22. Marshall, S.M., Schneider, K.R., Cisneros, K.V., et al. Determination of antioxidant capacities, $\alpha$-dicarbonyls, and phenolic phytochemicals in Florida varietal honeys using HPLC-DAD-ESI-MSn. (2014) J Agric Food Chem 62(34): 8623-8631.
23. Tsuji, M., Yamamoto, H., Sato, T., et al. Dietary quercetin inhibits bone loss without effect on the uterus in ovariectomized mice. (2009) J Bone Miner Metab 27(6): 673-681.

24. Lee, W.S., Lee, E.G., Sung, M.S., et al. Kaempferol inhibits IL-1 $\beta$-stimulated, RANKL-mediated osteoclastogenesis via downregulation of MAPKs, c-Fos, and NFATc1. (2014) Inflammation 37(4): $1221-1230$.

25. Kim, T.H., Jung, J.W., Ha, B.G., et al. The effects of luteolin on osteoclast differentiation, function in vitro and ovariectomy-induced bone loss. (2011) J NutrBiochem 22(1): 8-15.

26. Sakai, K., Aramaki, K., Takasaki, M., et al. Effect of dietary shortchain fructooligosaccharides on the cecalmicroflora in gastrectomized rats. (2001) BiosciBiotechnolBiochem 65(2): 264-269.

27. Roberfroid, M., Gibson, G.R., Hoyles, L., et al. Prebiotic effects: metabolic and health benefits. (2010) Br J Nutr 104(Suppl 2): S1-S63.

28. Lutz, T., Scharrer, E. Effect of short-chain fatty acids on calcium absorption by the rat colon. (1991) ExpPhysiol 76(4): 615-618.

29. Weston, R.J., Brocklebank, L.K. The oligosaccharide composition of some New Zealand honeys. (1999) Food Chem 64(1): 33-37.

30. Ariefdjohan, M.W., Martin, B.R., Lachcik, P.J., et al. Acute and chronic effects of honey and its carbohydrate constituents on calcium absorption in rats. (2008) J Agric Food Chem 56(8): 2649-2654.

31. Kaewprasert, S., Okada, M., Aoyama, Y. Nutritional effects of cyclodextrins on liver and serum lipids and cecal organic acids in rats. (2001) J NutrSciVitaminol (Tokyo) 47(5): 335-339.

32. Chepulis, L., Starkey, N. The long-term effects of feeding honey compared with sucrose and a sugar-free diet on weight gain, lipid profiles, and DEXA measurements in rats. (2008) J Food Sci 73(1): H1-H7. 33. Jung, C.H., Cho, I., Ahn, J., et al. Quercetin reduces high-fat diet-induced fat accumulation in the liver by regulating lipid metabolism genes. (2013) Phytother Res 27(1): 139-143.

34. Phuwamongkolwiwat, P., Suzuki, T., Hira, T., et al. Fructooligosaccharide augments benefits of quercetin-3-O- $\beta$-glucoside on insulin sensitivity and plasma total cholesterol with promotion of flavonoid absorption in sucrose-fed rats. (2014) Eur J Nutr 53(2): 457-468.

35. Chepulis, L.M., Francis, E. An initial investigation into the anti-inflammatory activity and antioxidant capacity of alpha-cyclodextrin-complexedManuka honey. (2012) J Complement Integr Med 9: 25.
Online ISSN: 2377-0619

Journal Title: International Journal Food and Nutritional Science Journal Short Name: Int J Food Nutr Sci
Ommega Online Publishers

E-mail: editor.foodscience@ommegaonline.com Website: www.ommegaonline.org 